\title{
Wavelength-dependent Effect of Tetra(m-hydroxyphenyl)chlorin for Photodynamic Therapy in an 'Early' Squamous Cell Carcinoma Model
}

\author{
S. ANDREJEVIC BLANT ${ }^{a}, J-F$. THEUMANN $^{b}$, M. FORRER $^{b}$, G. WAGNIËRES $^{b}$, \\ H. VAN DEN BERGH ${ }^{b}$, Ph. MONNIER ${ }^{a}$ \\ ${ }^{a}$ Department of Otolaryngology, Head and Neck Surgery, CHUV Hospital, Lausanne, Switzerland \\ ${ }^{b}$ Institute of Environmental Engineering, EPFL, Lausanne, Switzerland \\ Correspondence to S. Andrejevic Blant, Department of Otolaryngology, Head and Neck Surgery, CHUV Hospital, BH 10, \\ 1011 Lausanne, Switzerland
}

Received 20 June 1996; accepted in final form 16 December 1996

\begin{abstract}
The purpose of the present study was to correlate the wavelength of the irradiation source with the phototoxic activity of tetra(m-hydroxyphenyl)chlorin (mTHPC) in healthy and neoplastic mucosae. The hamster tumour model for early squamous cell carcinoma was used in these experiments. In vitro and in vivo studies have shown that mTHPC absorbs significantly at $652 \mathrm{~nm}(1,2)$. This wavelength is used currently in clinical mTHPC photodynamic therapy (PDT) trials. In order to study the wavelength dependence of the phototoxic effect on normal and tumour tissues, irradiation tests were performed 4 days after injection of $0.5 \mathrm{mg} \mathrm{kg}{ }^{-1} \mathrm{mTHPC}$. An argon-ion pumped dye laser was used as the light source. The light dose of $12 \mathrm{~J} \mathrm{~cm}^{-2}$ was delivered at a light dose rate of $150 \mathrm{~mW} \mathrm{~cm}{ }^{-2}$. The wavelength was varied between 642.5 and $665 \mathrm{~nm}$ at $2.5-\mathrm{nm}$ increments. The PDT damage was evaluated in serial Haematoxylin and Eosin stained sections using a tissue-damage scale. Light between 647.5 and $652.5 \mathrm{~nm}$ induced the highest damage to both the healthy and tumour mucosae. At wavelengths equal to or below $645 \mathrm{~nm}$, and equal to or above $655 \mathrm{~nm}$, tissue damage decreased. Wavelengths below $642 \mathrm{~nm}$ and above $660 \mathrm{~nm}$ did not induce any visible tissue damage. These results suggest that the in vivo optimal wavelength range for PDT with mTHPC is between 647 and $652 \mathrm{~nm}$. This information is essential for selecting an appropriate light source.
\end{abstract}

\section{INTRODUCTION}

Photodynamic therapy (PDT) is emerging as a minimally invasive alternative for the treatment of early squamous cell carcinomas (SCCs) in hollow organs (3-6). In head and neck cancers, the advantage of PDT compared to conventional modalities, such as surgery, radiation or chemotherapy, lies in the prevention of excessive tissue loss and of significant functional disorders (7).

Successful PDT involves the optimization of a large number of parameters. Among them are the type of photosensitizer (PS) including the mode and vehicle used for its administration, the drug dose, the wavelength of the light, the light dose, the light dose rate and the drug-light interval. In addition to these parameters, the wavelength of the light used in PDT is obviously crucial for optimizing the therapeutic effect. As it is difficult to evaluate all of these variables in a clinical context, the use of an animal model may provide preclinical data relevant to clinical trials of PDT. For this reason, 'early' SCCs, chemically induced using 7,12-dimethylbenz(a)anthracene (DMBA) in the cheek pouch of the Syrian hamster (8), have been chosen for this study. In both histology and immunohistochemistry, this tumour model mimics human carcinogenesis in the upper aero-digestive tract and oesophagus (9-11).

Wavelength dependence has been studied in vivo and in vitro with different secondgeneration PSs such as phthalocyanines 


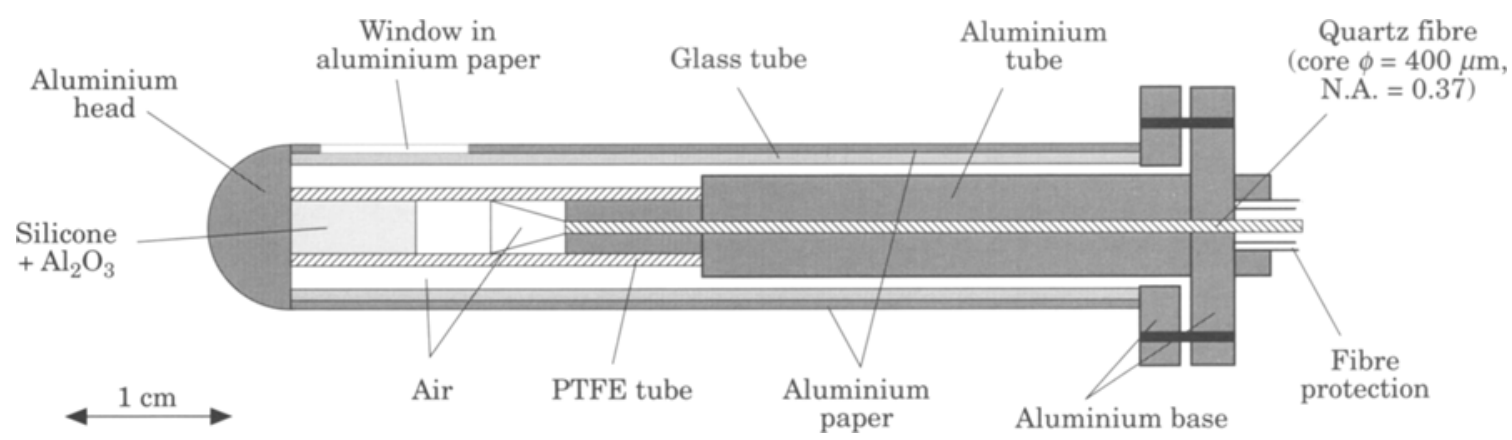

Fig. 1. Light distributor used for irradiation of the hamster cheek pouch mucosa.

$(12,13)$, BPD-MA (14) and 5-ALA (15). With many PSs, wavelength shifts are observed between the absorption maxima measured in solvents and the most effective PDT wavelength in vivo $(12,13)$. Such shifts can be due to different factors such as the localization of the PS in different tissues and tissue compartments as well as tissue absorption properties, the production of singlet oxygen, or the physico-chemical environment (16).

To measure the PDT 'action spectrum' around $652 \mathrm{~nm}$, irradiation tests between 642.5 and $665 \mathrm{~nm}$ were performed. Results were compared with the fluorescence excitation spectrum of mTHPC measured in vivo, and its absorption spectrum measured in vitro $(1,2)$. To the best of the authors' knowledge, this information is not available for mTHPC.

\section{MATERIALS AND METHODS}

\section{Animal model}

Carcinogenesis in the hamster cheek pouch was chemically induced (BRL, Fuellinsdorf, Switzerland) according to methods that have been described previously (17). Briefly, the early SCC (carcinoma in situ and microinvasive carcinoma) was produced by topical application of $0.5 \%$ oily DMBA (Sigma Chemicals Co. St Louis, USA) solution in the left cheek pouch mucosa thrice weekly over 10 weeks. The contralateral cheek pouch, which was not painted with DMBA, served as control. The animals were housed at room temperature with a 12-h light/dark cycle. Food and drinking water were given ad libitum. All experiments were performed under intraperitoneal anaesthesia (ketalar $150 \mathrm{mg} \mathrm{kg} \mathrm{kg}^{-1}$ and xylesine $15 \mathrm{mg} \mathrm{kg}^{-1}$ ) and in accordance with protocols approved by the experimental animal ethics committee.

\section{Photodynamic therapy}

Tetra(m-hydroxyphenyl)chlorin (mTHPC) was supplied in powder form by Scotia Pharmaceuticals Ltd (Guildford, UK). Prior to utilization, it was dissolved in a solution of $30 \% \mathrm{v} / \mathrm{v}$ polyethylene glycol $400,20 \% \mathrm{v} / \mathrm{v}$ ethanol and $50 \% \mathrm{v} / \mathrm{v} \quad \mathrm{H}_{2} \mathrm{O}$. Photodynamic therapy on tumour-bearing and contralateral healthy cheek pouch mucosae was performed 4 days after an intracardiac injection of $0.5 \mathrm{mg} \mathrm{kg}^{-1}$ body weight mTHPC (18). Irradiation conditions were adapted to those applied in clinical trials (19). The light dose of $12 \mathrm{~J} \mathrm{~cm}^{-2}$ was delivered at a rate of $150 \mathrm{~mW} \mathrm{~cm}{ }^{-2}$. This light intensity is not sufficient to induce a thermal effect in tissues (20). Photodynamic therapy was carried out with wavelengths between 642.5 and $665 \mathrm{~nm}$ at $2.5-\mathrm{nm}$ increments.

\section{Light source and light delivery}

An argon-ion pumped dye laser system [SpectraPhysics Model 2045 (20 W continuous wave in the visible) and Spectra-Physics Model 375 B dye laser], operated with 4-dicyanomethylene2-methyl-6-(p-dimethylaminostyryl)-4H-pyran (DCM) dye (LC 6500 from Lambda Physics) was used as the light source. The DCM dye allows the laser to be tuned between 600 and $695 \mathrm{~nm}$. The wavelength is tuned with a birefringent filter (Spectra-Physics, Model 573-94) located in the dye laser cavity, and the wavelength is verified with a monochromator [Jobin-Yvon, Model $\mathrm{H} \mathrm{10}$, Precision: $0.2 \mathrm{~nm}$ full width half maximum (FWHM)]. The light was applied using a $1 \mathrm{~cm}$ diameter cylindrical distributor equipped with a lateral circular window (Fig. 1). The light delivered by an optical quartz fibre to the light diffuser is expanded through a small air space, and passes into a cylindrical rod that contains a transparent 
silicone polymer loaded with $\mathrm{Al}_{2} \mathrm{O}_{3}$ particles in order to scatter the light. The aluminium end mirror and the concentration of particles along the main axis of this cylinder are chosen to give a homogenous light distribution at the surface of the outer cylinder. Careful positioning of the light diffuser in the hamster cheek pouch in direct contact with the buccal mucosa offers a high reproducibility in the light dosimetry.

\section{Analysis of PDT-induced tissue damage}

The animals were killed, using an overdose of the same anaesthetics as mentioned above, $96 \mathrm{~h}$ after irradiation, which corresponds to the time of maximal mucosal damage. The procedure used for taking biopsies has been described previously (21). The entire tumoral and healthy cheek pouches were resected, and lesions were divided into two equal specimens. One was fixed in $5 \%$ buffered formalin ( $\mathrm{pH} 7.0$ ), paraffin-embedded, sectioned in $5-\mu \mathrm{m}$ thick slices and stained with Haematoxylin and Eosin (H\&E) for standard histological examination. For each animal, the whole necrotic area was examined in serial sections stained with $\mathrm{H} \& \mathrm{E}$ to evaluate the depth of the mucosal destruction. The other part of the excised lesion was frozen immediately in liquid nitrogen by contact with an isopentane slush, and cut at cryogenic temperatures in $5-\mu \mathrm{m}$ thick slices. These were used in some cases for additional histochemical myosin-ATP-ase and NADH-diaphorase staining techniques, which are especially useful for assessing the degree of damage to striated muscles $(22,23)$. Following the enzymatic reaction, counterstaining with Haemalun allowed the delineation between necrotic and healthy layers to be demonstrated.

In order to evaluate the histological depth of PDT damage on different mucosal layers, such as epithelium, lamina propria or striated muscle, a four-graded tissue-damage scale was used. On this scale, Grade 1 corresponds to the destruction of the epithelium. In Grade 2, the necrosis extends to the lamina propria. Grade 3 corresponds to a necrosis that reaches the striated muscle, and in Grade 4, all mucosal layers are destroyed. Tissue damage up to Grade 2 was estimated as an insufficient effect. Grades 2 and 3 were judged as an 'optimal' PDT response, and Grade 4 necrosis was considered to be an overdose response. The
Table 1. Tissue damage scale

Grade of

tissue damage

Histology

\begin{tabular}{ll}
\hline 0 & No tissue destruction \\
1 & $\begin{array}{l}\text { Destruction of the epithelium } \\
\text { Destruction of the epithelium } \\
\text { and the lamina propria } \\
2\end{array}$ \\
3 & $\begin{array}{l}\text { Destruction of the epithelium, } \\
\text { the lamina propria and the } \\
\text { striated muscle } \\
\text { Destruction of all layers resulting } \\
\text { in transmural necrosis }\end{array}$
\end{tabular}

Grades 0 and 1 are estimated as insufficient, 2 and 3 as optimal and 4 as overdose responses.

grades of necrosis and evaluation of the tissue damage are summarized in Table 1 . This nonlinear, morphological scale has been chosen because massive (although not always observed) interstitial oedema of the mucosal wall hinders reproducible micrometric measurements of the tissue damage. This means that when a marked oedema is present, the absolute measurement of the depth of necrosis could be increased artificially as compared to the same necrosis in a non-oedematous cheek pouch.

\section{Statistical analysis}

The results of irradiation performed on the healthy and tumour mucosae were evaluated as depths of tissue damage graded from 0 to 4 using the scale described above. The statistical significance of the differences in tissue responses achieved at various wavelengths was determined using a non-parametric MannWhitney U-test ( $\alpha \leq 0.05)$.

\section{RESULTS}

Macroscopically, the first changes in the irradiated mucosae were observed $24 \mathrm{~h}$ after PDT as a diffuse oedema of the whole cheek pouch. The first visible tissue reaction matching the irradiation window appeared $48 \mathrm{~h}$ later, and achieved a maximum at $96 \mathrm{~h}$ after PDT. Figure 2 illustrates the results of the irradiation in terms of tissue damage to the healthy and neoplastic mucosae at 


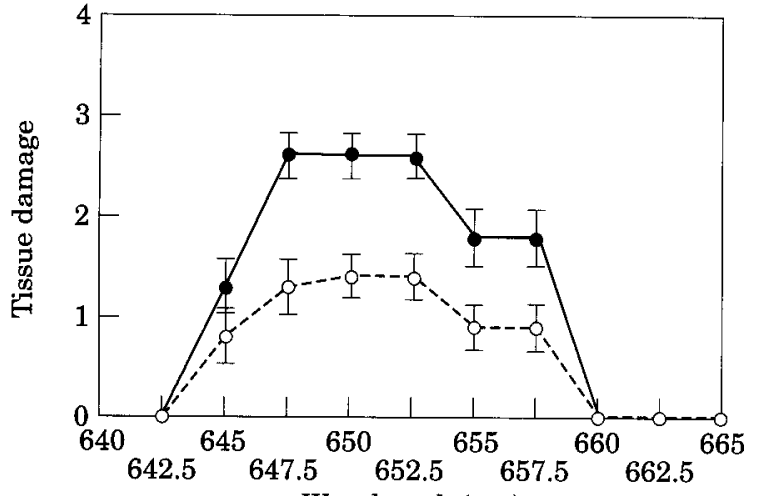

Wavelength (nm)

Fig. 2. Damage induced by photodynamic therapy (PDT) on healthy and neoplastic hamster cheek pouch mucosae 4 days after injection of $0.5 \mathrm{mg} \mathrm{kg}^{-1} \mathrm{mTHPC}$. The fluence of $12 \mathrm{~J} \mathrm{~cm}^{-2}$ was delivered at a fluence rate of $150 \mathrm{~mW} \mathrm{~cm}^{-2}$. The wavelength was varied from 642.5 to $665 \mathrm{~nm}$ in $2.5-\mathrm{nm}$ increments. Light delivered between 647.5 and $652.5 \mathrm{~nm}$ induced maximal damage to both tumour-bearing $(\bullet)$ and healthy $(0)$ mucosae. At these wavelengths, significantly higher PDT damage was noted for early squamous cell carcinoma as compared to the healthy mucosa $(\alpha \leq 0.05)$. At 645,655 and $657 \mathrm{~nm}$, less pronounced tissue damage was observed for both mucosae. Light applied at wavelengths below 642.5 and over $660 \mathrm{~nm}$ did not induce any visible tissue damage. Data points represent mean tissue damage for five animals, as determined by the rating scale described in the text. Error bars are \pm 1 standard deviation. The significance of the differences in tissue responses achieved at various wavelengths was determined using a non-parametric Mann-Whitney U-test ( $\alpha \leq 0.05)$.

wavelengths ranging from 642.5 to $665 \mathrm{~nm}$. Light delivered between 647.5 and $652.5 \mathrm{~nm}$ induced maximal damage to both the healthy and tumour-bearing mucosae. At these wavelengths, significantly higher damage from PDT was noted for early SCC as compared to the healthy mucosa $(\alpha \leq 0.05)$. With the same light dose delivered at 645,655 and $657 \mathrm{~nm}$, less pronounced tissue damage was observed for both mucosae $(\alpha \leq 0.05)$. Light at wavelengths below 642.5 and over $660 \mathrm{~nm}$ did not induce any visible tissue damage.

\section{DISCUSSION}

This in vivo study has shown that in the red part of the spectrum, wavelengths between 647 and $652 \mathrm{~nm}$ induce the greatest amount of tissue damage in both the healthy and tumourbearing mucosae. The range of wavelengths $(647-652 \mathrm{~nm})$ over which PDT of early SCC is most effective in this particular tumour model suggests that for early cancers in hollow organs, fairly broad-band light sources can be used while retaining a maximum phototoxic effect.

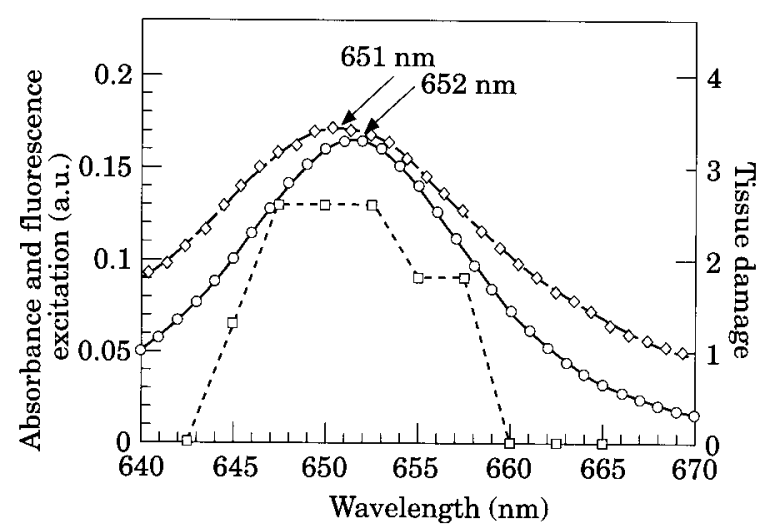

Fig. 3. The in vitro absorption spectrum of $5 \mu \mathrm{M} \mathrm{mTHPC}$ in phosphate-buffered saline (PBS) solution supplemented with $10 \%$ bovine serum (o) as well as the in vivo fluorescence excitation spectrum $(\diamond)$ and the photodynamic therapy tissue damage 'action spectrum' ( $\square$ ) are compared. The fluorescence excitation peaks are at nearly the same wavelengths as the absorption peaks (absorption in vitro $652 \pm 1 \mathrm{~nm}$ and fluorescence excitation in vivo $651 \pm 0.5 \mathrm{~nm}$ ). Fluorescence excitation and absorption curves have patterns in the red region $(647-652 \mathrm{~nm})$ that are similar to those of the tissue-damage curve.

The mTHPC-PDT tissue damage curve can be compared to either the in vitro absorption spectrum or the in vivo excitation signal as shown in Fig. 3. The in vitro absorption curve of $5 \mu \mathrm{M}$ mTHPC in phosphate-buffered saline (PBS) supplemented with $10 \%$ bovine serum shows its absorption maximum in the red to be $652 \mathrm{~nm}$ $(1,2,24)$. The in vivo fluorescence excitation spectrum of mTHPC measured with a fibrebased optical multichannel analyser (25) on the healthy and tumour-bearing cheek pouch mucosae has a fluorescence excitation peak at nearly the same wavelength (M. Forrer, unpubl. data). The slight difference between these spectra can be attributed to two factors: first, the difference in precision of the two methods used; and second, the influence of the optical tissue absorption and scattering on the fluorescence excitation spectra (26). The fluorescence absorption and excitation spectra are similar in form to the tissue-damage curve. The region of pronounced tissue damage is situated between 647.5 and $652.5 \mathrm{~nm}$. These wavelengths correspond to equal fluorescence excitation and absorption intensities on either side of the fluorescence excitation and absorption maxima. In contrast to observations reported for some of the other compounds used in PDT (1), there seems to be no wavelength shift between the absorption, excitation and tissue-damage response curves in the red part of the spectrum.

In the present experiments, the highest PDT efficacy was achieved at wavelengths of 
$650 \pm 2.5 \mathrm{~nm}$ using an argon-ion pumped dye laser with a $0.2 \mathrm{~nm}$ FWHM. Recent developments in diode laser technology offer highpower devices with several nanometre bandwidths (27). The results obtained here suggest that such diode lasers can be used as appropriate light sources without a significant loss of PDT efficacy.

\section{ACKNOWLEDGEMENTS}

This work was supported by the Swiss National Science Foundation (Grant No. 31 43395.95), by the CHUV-UNILEPFL Programme for collaborative research in biomedical technology and by the Swiss Priority Programme in Optics. The authors wish to thank G. Metthez and V. Groux for technical assistance. Finally, the authors gratefully acknowledge Scotia Pharmaceuticals Ltd, Guildford, UK for providing the mTHPC.

\section{REFERENCES}

1 Braichotte D, Savary JF, Glanzmann $\mathrm{T}$ et al. Clinical pharmacokinetic studies of tetra(metahydroxyphenyl)chlorin in squamous cell carcinoma by fluorescence spectroscopy at 2 wavelengths. Int $J$ Cancer 1995, 63:198-204

2 Ma L, Moan J, Berg K. Evaluation of a new photosensitizer, meso-tetra-hydroxyphenyl-chlorin, for use in photodynamic therapy: a comparison of its photobiological properties with those of two other photosensitizers. Int $J$ Cancer 1994, 57:883-8

3 Edell ES, Cortese DA. Photodynamic therapy in the management of early superficial squamous cell carcinoma as an alternative to surgical resection [see comments]. Chest 1992, 102:1319-22

4 Grant WE, Hopper C, Speight PM et al. Photodynamic therapy of malignant and premalignant lesions in patients with 'field cancerization' of the oral cavity. $J$ Laryngol Otol 1993, 107:1140-5

5 Monnier $\mathrm{P}$, Fontolliet $\mathrm{C}$, Wagnières $\mathrm{G}$ et al. Further appraisal of PDI and PDT of early squamous cell carcinomas of the pharynx, oesophagus and bronchi. In: Spinelli P, de Fante M, Marchesini R, (eds) Photodynamic Therapy and Biomedical Lasers, Vol. 1011. Milan: Exerpta Medica, 1992: 36 87

6 Monnier P, Savary M, Fontolliet C et al. Photodetection and Photodynamic therapy of "early" squamous cell carcinomas of the pharynx, oesophagus and tracheo-bronchial tree. Lasers Med Sci 1990, 5:149-69

7 Biel MA. Photodynamic therapy of head and neck cancers. Sem Surg Oncol 1995, 11:355-9

8 Salley J. Experimental carcinogenesis in cheek pouch of the Syrian hamster. $J$ Den Res 1954, 33:253-62

9 Gimenez-Conti IB, Shin DM, Bianchi AB et al. Changes in keratin expression during 7,12-dimethylbenz[a]anthracene-induced hamster cheek pouch carcinogenesis. Cancer Res 1990, 50:4441-5

10 Hurlimann J, Gardiol D. Immunohistochemistry of dysplasias and carcinomas of the esophageal epithelium. Pathol Res Pract 1989, 184:567-76

11 Mufti SI, Zirvi KA, Garewal HS. Precancerous lesions and biologic markers in esophageal cancer. [Review]. Cancer Detect Prevent 1991, 15:291-301
12 Canti G, Lattuada D, Leroy E et al. Action spectrum of photoactivated phthalocyanine AIS2Pc in tumor bearing mice. Anti-Cancer Drugs 1992, 3:139-42

13 Griffiths J, Cruse-Sawyer J, Wood SR et al. On the photodynamic therapy action spectrum of zinc phthalocyanine tetrasulphonic acid in vivo [see comments]. J Photochem Photobiol B Biol 1994, 24:195-9

14 Waterfield EM, Renke ME, Smits $\mathrm{CB}$ et al. Wavelength-dependent effects of benzoporphyrin derivative monoacid ring $A$ in vivo and in vitro. Photochem Photobiol 1994, 60:383-7

15 Szeimies RM, Abels C, Fritsch C et al. Wavelength dependency of photodynamic effects after sensitization with 5-aminolevulinic acid in vitro and in vivo. J Investig Dermatol 1995, 105:672-7

16 Arnfield MR, Mathew RP, Tulip J et al. Analysis of tissue optical coefficients using an approximate equation valid for comparable absorption and scattering. Phys Med Biol 1992, 37:1219-30

17 Andrejevic S, Savary JF, Fontolliet $\mathrm{C}$ et al. 7,12dimethylbenz[a]anthracene-induced 'early' squamous cell carcinoma in the Golden Syrian hamster: evaluation of an animal model and comparison with 'early' forms of human squamous cell carcinoma in the upper aero-digestive tract. Int $J$ Exp Pathol 1996, 77:7-14

18 Andrejevic S. Evaluation de nouveaux photosensibilisateurs pour la photothérapie des carcinomes épidermoïdes des voies aéro-digestives supérieures: apport d'un modèle animal. In: Problèmes Actuels d'Otorhinolaryngologie, Vol. 19. Bern: Haus Hubert, 1996: 300-8

19 Grosjean P, Savary J, Mizeret J et al. Photodynamic therapy for cancer of the upper aerodigestive tract using tetra(m-hydroxyphenyl)chlorin. J Clin Care Med Surg 1996, 14:281-7

20 van Gemert MJ, Welch AJ. Time constants in thermal laser medicine. Lasers Surg Med 1989, 9:405-21

21 Andrejevic-Blant $\mathrm{S}$, Woodtli $\mathrm{A}$, Wagnières $\mathrm{G}$ et al. In vivo fluence rate effects in Photodynamic Therapy performed at two wavelengths in an "early" squamous cell carcinoma model with tetra(mhydoxyphenyl)chlorin. Photochem Photobiol 1996, 64: 963-8

22 Padykula H, Herman E. The specificity of the histochemical method for adenosine triphosphate. J Histochem Cytochem 1954, 3:170-88

23 Neumann RA, Leonhartsberger H, Pieczkowski F et al. Accurate histochemical definition of argon-laserinduced tissue necrosis. Dermatology 1992, 184:202-4

24 Pass HI. Photodynamic therapy in oncology: mechanisms and clinical use. [Review]. $J$ Nat Cancer Inst 1993, 85:443-56

25 Forrer M, Glanzmann T, Mizeret J et al. Fluorescence Excitation and Emission Spectra of ALA-induced Protoporphyrin IX in Normal and Tumoral Tissue of the Human Bladder. International Society for Optical Engineering, 1995: 84-8

26 Bays $R$, Wagnieres $G$, Robert $D$ et al. Clinical determination of tissue optical properties by endoscopic spatially resolved reflectometry. Appl Optics 1996, 35: $1756-66$

27 Welch F, Geifres D. High power 8-5W cw, visible laser diodes. Elect Lett 1991, 27:21

Key words: Photodynamic therapy; Photosensitizer; Early squamous cell carcinoma; Cheek pouch; Wavelength 